\title{
Carcinoma Middle Ear with Facial Nerve Palsy and Temporal Lobe Abscess
}

\author{
*MA Chowdhury ${ }^{1}$, SMG Rabbani ${ }^{2}$, M Asaduzzaman $^{3}$, M Malakar $^{4}$ \\ ${ }^{1}$ Prof. (Dr.) M. Alamgir Chowdhury, Professor \& Head, Otolaryngology - Head \& Neck Surgery \\ Anwer Khan Modern Medical College. Dhaka, Email: jaldi@dhaka.net \\ ${ }^{2}$ Dr. SM Golam Rabbani, Assistant Professor, Otolaryngology - Head \& Neck Surgery, Tairunnessa \\ Memorial Medical College \& Hospital, Boardbazar, Gazipur \\ ${ }^{3}$ Dr. Md. Asaduzzaman, Assistant Registrar, Otolaryngology - Head \& Neck Surgery, Medical College \\ for Women \& Hospital, Uttara, Dhaka \\ ${ }^{4}$ Dr. Mousumi Malakar, Medical Officer, Otolaryngology - Head \& Neck Surgery, Medical College for \\ Women \& Hospital, Uttara, Dhaka
}

*Corresponding Author

\begin{abstract}
Carcinoma of middle ear is very rare condition being one in 20,000 new patients. The commonest primary middle ear malignancy is usually squamous cell carcinoma. A 36-year-male presented with right sided severe earache with blood stained aural discharge, associated with headache and deviation of angle of the mouth to the opposite side. He had ear discharge since childhood. On examination he had bleeding polypoidal mass in the right external auditory canal \& tympanic membrane was not visualized. He also had features of facial nerve palsy. CT scan of brain finding was chronic right mastoiditis \& right temporal lobe abscess causing significant mass effect. The patient was undergone Burr-hole operation. After 2 weeks right radical mastoidectomy was done. There was huge granulation tissue involving middle ear, attic \& mastoid antrum and ossicles was eroded. Histopathology report revealed infiltrating squamous cell carcinoma grade-I. The patient was sent for radiotherapy \& asked for follow up monthly. In long standing chronic suppurative otitis media with blood stained discharge \& facial nerve palsy, middle ear malignancy should be suspected.
\end{abstract}

Key words: Carcinoma middle ear, facial nerve palsy, temporal lobe abscess.

\section{Introduction}

Carcinoma Middle ear is very rare condition being one in 20,000 new patients ${ }^{1}$. Long standing middle ear suppuration thought to predispose it. May some time develops in a radical mastoidectomy cavity. It can go any direction, outwards into meatus and thence into parotid or into post auricular region, upwards into middle cranial fossa, backwards into mastoid, downwards into jugular fossa, inwards into inner ear and petro-sphenoid angle, may invade the facial nerve in the tympanic course, forwards in tissue planes around the Eustachian tube to the post nasal space. Lymphatic metastases are late and usually in retropharyngeal nodes- Rouviere's node over the transverse process of the atlas.

\section{Case report}

A 36-year-old male businessman by occupation came to our hospital with severe earache $\&$ headache in right side for 2 weeks, facial palsy of right side for 2 weeks, Right ear discharge since childhood. But for the last 4 weeks it was blood stained.

Otoscopy reveals blood mixed discharge and polypoidal mass full in the right external auditory canal which foul smelled and tympanic membrane was not visualized. The patient was anxious looking and drowsy.

Tuning fork test shows Rinne negative in right ear and Weber lateralized to right ear. Facial nerve test reveals wrinkling of forehead absent on right side, angle of the mouth deviated to opposite side and unable to close right eye. 
Spiral CT scan of brain shows chronic right mastoiditis and right sided temporal lobe brain abscess.

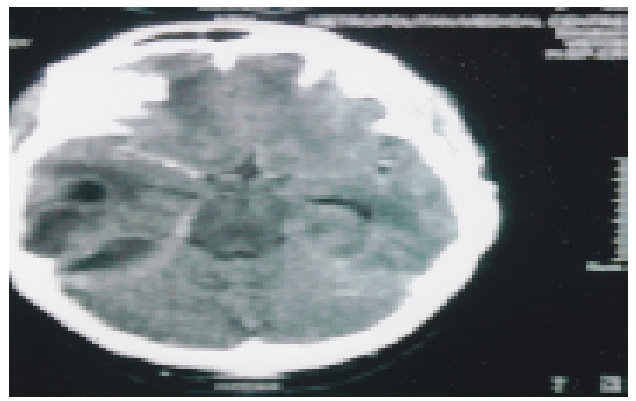

Figure 1: CT scan of brain showing right temporal lobe abscess.

Medical treatment with high dose intravenous antibiotics ceftriaxone, metronidazole, analgesic for pain and steroids was given.

Neurosurgical treatment Barr-hole aspiration of temporal lobe abscess was done on 21.06.2011and $17 \mathrm{ml}$ of pus came out. Stitches were removed after 14 days. After then radical mastoidectomy was done. Mastoid cavity opened by drilling and extensive cholesteatoma found, it was removed. Then middle ear cavity opened and it was full of granulation tissue, which was removed.

Ossicles are eroded. Mastoid air cells were necrosed and fragile, meticulous removal was done. Wide meatotomy done, pack given, wound closed in layers. Mastoid bandage applied. Post operative recovery was uneventful. Tissue was sent for histopathology. It showed infiltrating squamous cell carcinoma grade I. The patient was referred to oncologist for further treatment.

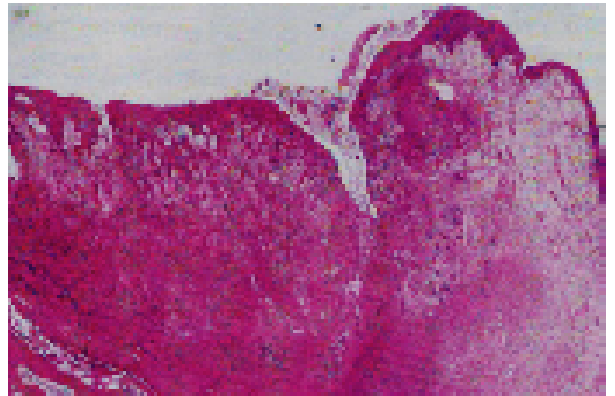

Figure 2: Photograph of histopathology

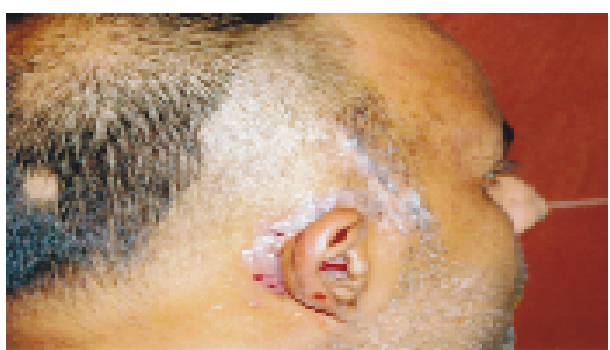

Figure 3: Post-operative photo of the patient.

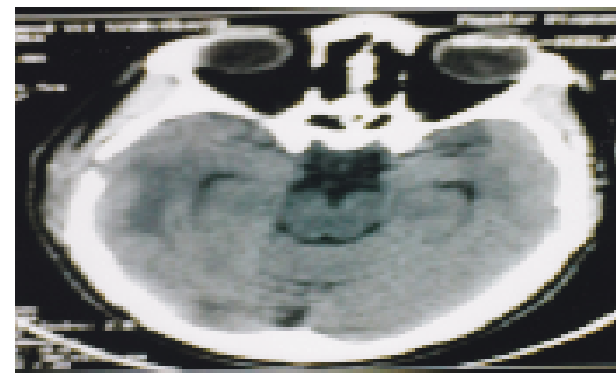

Figure 4: Post operative CT scan with healed abscess.

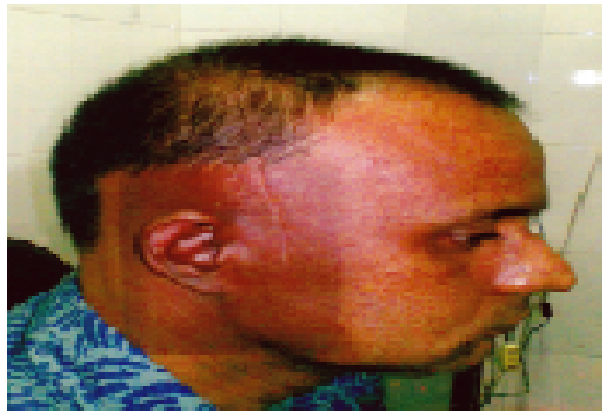

Figure 5: Photograph of the patient as on October 17, 2011

\section{Discussion}

Squamous cell carcinoma is the commonest middle ear malignancy whereas adenocarcinoma is rare. More than one third of middle ear squamous cell carcinomas (SCC) are preceded by chronic suppurative otitis media (CSOM). Carcinoma following chronic suppurative otitis media is reported to be cases per 4000 of CSOM $^{1}$. SCC accounts for $60-80 \%$ of the carcinoma of the temporal bone ${ }^{2}$. The coexistence of CSOM with or without cholesteatoma alone with malignancy poses several diagnostic and therapeutic challenges for the clinician. Most commonly it occurs in sixth 
decade but our patient is only 36 years. Different study shows more than half of the patients have long standing middle ear infection. Kenyon et al confirmed that a history of chronic suppuration with or without cholesteatoma predispose the patient to tumor development and that, in the presence of continuing otorrhoea, patient were not protected by mastoid surgery ${ }^{3}$. Blood stained otorrhoea is usually present which the patient had. Males and females are equally affected. Granulation tissue and polyp formation which readily bleed on touch should always arouse suspicion of malignancy. Biopsy will always distinguish it from inflammatory condition or from glomus tumour. Biopsy may be done through tympanotomy. Routine cytology of discharge will often detect presence malignant cells. Deafness is conductive type, until the labyrinth is involved in later stages. Our patient had conductive deafness and lower motor neuron type of facial nerve palsy. Not uncommon and usually late but the patient develop early. Other cranial nerve palsies are late signs and preclude any chances of cure. There are several routes by which sepsis may spread to the cranial cavity from an infected ear and indeed, considering dura to the infective process, in many cases it is surprising that intracranial complications are not so common. These routes are most commonly by direct erosion of osteitic bone by inflammatory process or via infective thrombophlebitis of emissary veins traversing bone and also dura. In intracranial abscess the presentation is often much more insidious with low grade headache, mild pyrexia and in the later stages drowsiness, lethargy, and weakness. The prominent symptoms are headache and vomiting. The frequency of and mortality from brain abscess has remarked in recent years, with mortality of $6-14 \%$ quoted in one series ${ }^{4}$.

Accurate assessment of the extent of the tumour is by high resolution CT scan ${ }^{5}$, this is important in the subsequent staging and management of the tumour. Additional valuable information can be obtained from MRI were there is suspicion of vascular involvement.

Treatment modalities include primary surgery with a post surgical radiation in most patients; this is the preferred option ${ }^{6,7,8}$. Radiotherapy alone is considered inadequate treatment. The standard treatment for early tumour is radical mastoidectomy with postoperative radiotherapy ${ }^{8,9}$.

These tumors retain a poor prognosis despite the development of increasingly radical surgical procedures and the advantages of radiotherapy. About $25 \%$ or less can expect 5 years survival after treatment at specialized centers ${ }^{8}$. No cure can be looked for when cranial nerve palsies are present or CT scan shows the diseases beyond the confines of the temporal bone. Death results from involvement of brain and meninges by direct spread, or inanition due to intractable pain.

\section{Conclusion}

In-longstanding CSOM a sudden onset of sinister symptoms like facial nerve palsy, blood stained discharge from middle ear and severe earache should alert the development of malignancy. Because Middle ear carcinoma has a poor prognosis, it is important to detect lesion early.

\section{References}

1. Robinson GA. Malignant tumors of the ear. Laryngoscope 1931; 41: 467-73.

2. Morton RP, Stell PM, Derrick PP. Epidemiology of Cancer of middle ear cleft. 1984; 53: 1612-17.

3. Kenyon GS, Marks PV, Scholtz CL. Squamous cell carcinoma of middle ear- A 25 year study. Ann Otol Rhinol Laryngol 1985; 94: 273-77.

4. Taylor JC. The case for excision in the treatment of brain abscess. 1987; 1: 273-8.

5. Bird CR, Hasso AAN, Stewart CE, et al. Malignant primary neoplasm's of the ear and temporal bone studies by high-resolution computed tomography. 1983; 149: 171-72.

6. Olsen KD, DeSanto LW, Forbes GS. Radiographic assessment of squamous cell carcinoma of the temporal bone. Laryngoscope 1983; 93: 1162-67.

7. Schwager K, Pfreunder L, Hoppe F, et al. Carcinoma of the external ear canal and middle ear as inter disciplinary challenge for ear surgery and radiotherapy. Laryngorhinootologie 2001; 80: 196-202.

8. Tucker WN. Cancer of middle ear, a review of 89 cases. $1964 ;$ 18: 642-50.

9. Barrs DM. Temporal bone carcinoma in skull base tumour surgery. Otolaryngol Clin North Am 2001; 34(6): 1197-1218. 